\title{
PENATAAN TERINTEGRASI PURA DALEM DESA GUNAKSA KECAMATAN DAWAN KABUPATEN KLUNGKUNG
}

\author{
I N. Susanta ${ }^{1}$, I G. W. Laskara ${ }^{2}$, N. M. Swanendri ${ }^{3}$ dan G. A. M. Suartika ${ }^{4}$
}

\begin{abstract}
ABSTRAK
Pura Dalem Desa Gunaksa merupakan salah satu dari pura kahyangan tiga Desa Pakraman Gunaksa, Desa Gunaksa, Kecamayan Dawan, Kabupaten Klungkung. Pura Dalem Desa sebagai stana dan tempat pemujaan Tuhan dalam manifestasinya sebagai Siwa. Dalam kontek Tri Kona, Dewa Siwa sebagai pelebur/ pralina dari unsur-unsur kehidupan. Pura Dalem ini sebagai ulun setra, diempon dan disungsung oleh krama Desa Pakraman Gunaksa. Kegiatan keagamaan yang dilaksanakan meliputi: petirtan/piodalan, perayaan hari raya suci umat hindu dan kegiatan upacara yang terkait dengan manusa yadnya, butha yadnya dan pitera yadnya. Tidak efektifya area tanah pura, sedangkan di sisi lainnya natah yang ada dirasakan tidak cukup memadai dalam upacara tertentu. Kesadaran bahwa jika kondisi tersebut tidak hanya akan mengganggu kelancaran pelaksanaan aktivitas keagamaan, namun juga kenyamanan dan keyakinannya. Kondisi demikian telah mendorong pihak pengempon, pengurus dan pemangku untuk melakukan kegiatan penataan. Kegiatan penataan itu sendiri diawali dengan perencanaan yang didukung oleh civitas akademika Jurusan Arsitektur Universitas Udayana melalui kegiatan pengabdian 'Hibah Udayana Mengabdi'. Kegiatan perencaaan dan perancangan pada pengabdian ini terdiri dari beberapa tahap mulai dari permulaan/pengenalan, persiapan, pengajuan usul, evaluasi dan tindakan.
\end{abstract}

Kata kunci : penataan, integrasi, pura

\begin{abstract}
Pura Pura Dalem Gunaksa Village is one of the three temples of Pakraman Gunaksa village, Gunaksa village, Kecamayan Dawan, Klungkung regency. Pura Dalem Desa as the stana and place of worship of God in its manifestation as Shiva. In the context of Tri Kona, Lord Shiva as a fusible / pralina of the elements of life. Pura Dalem is as ulun setra, diempon and disungsung by krama Desa Pakraman Gunaksa. Religious activities carried out include: petirtan / piodalan, holy day celebrations and ceremonial activities associated with manusa yadnya, butha yadnya and pitera yadnya. Ineffective land area of the temple, whereas on the other hand the existing natah is not sufficient enough in certain ceremonies. The awareness that if the condition will not only disrupt the smooth implementation of religious activities, but also comfort and confidence. Such conditions have encouraged the pengempon, administrators and pemangku to conduct structuring activities. The arrangement activity itself was started with a plan supported by Udayana University Architecture Department's academic community through the dedication activity of 'Udayana Mengabdi Grant'. Planning and designing activities in this devotion consist of several stages from the beginning / introduction, preparation, proposal, evaluation and action.
\end{abstract}

Keywords: structuring, integration, temple

Keywords: Service, help, devotion, social

\footnotetext{
${ }^{1}$ Staf Pengajar Jurusan Arsitektur Fakultas Teknik Universitas Udayana, susanta@unud.ac.id

${ }^{2}$ Staf Pengajar Jurusan Arsitektur Fakultas Teknik Universitas Udayana, windu@.unud.ac.id

${ }^{3}$ Staf Pengajar Jurusan Arsitektur Fakultas Teknik Universitas Udayana,swanendri@ unud.ac.id

${ }^{4}$ Staf Pengajar Jurusan Arsitektur Fakultas Teknik Universitas Udayana, suartika@unud.ac.id
} 


\section{PENDAHULUAN}

Pura Dalem Desa Gunaksa merupakan salah satu dari pura kahyangan tiga Desa Pakraman Gunaksa, Desa Gunaksa, Kecamayan Dawan, Kabupaten Klungkung. Pura Dalem Desa sebagai stana dan tempat pemujaan Tuhan dalam manifestasinya sebagai Siwa. Dalam kontek Tri Kona, Dewa Siwa sebagai pelebur/ pralina dari unsur-unsur kehidupan. Pura Dalem ini sebagai ulun setra, diempon dan disungsung oleh krama Desa Pakraman Gunaksa. Kegiatan keagamaan yang dilaksanakan meliputi: petirtan/piodalan, perayaan hari raya suci umat hindu dan kegiatan upacara yang terkait dengan manusa yadnya, butha yadnya dan pitera yadnya.

Ativitas keagamaan yang inten membutuhkan pura dengan area dan fasilitas yang memadai dapat meningkatkan kenyamanan umat dalam melaksanakan pemujaan, oleh karena itu maka perlunya dibuat penataan baik pada palinggih maupun bangunan pendukungnya. Pura Dalem memiliki satu jalan akses, dikelilingi kebun masyarakat, di jeroan pura terdapat beberapa bangunan palinggih maupun bangunan pelengkap. Lingkungan di sekitar pura dan perkembangan penggunaan lahan yang cepat, memerlukan pengamanan terhadap batas-batas pura dengan mempertegas dan menata areaarea, sehingga membentuk mandala pura yang sesuai konsep tatanan pura, serta menjadi lebih luas dan leluasa.

Tujuan dari Penataan Pura Dalem Desa Gunakasa, Kecamatan Dawan, Kabupatan Klungkung, Bali ini adalah untuk dapat mewujudkan pura yang dapat mewadahi aktivitas umat keagamaan bagi umat Hindu di Desa Gunaksa dengan perbaikan konsep pembangunan, perbaikan bangunan-bangunannya, dan kelengkapan pura yang berkonsep ideal.

Kegiatan pengabdian masyarakat yang dilakukan oleh civitas akademika Fakultas Teknik ini bertujuan menyusun dokumen penataan yang komprehensif yang menjadi acuan bagi penataan pura dalam jangka pendek maupun jangka panjang.

Manfaat dari kegiatan Pengabdian Masyarakat ini dapat dirasakan langsung oleh pengempon selaku penanggungjawab pura dan masyarakat umat hindu di Desa Gunaksa serta umat sedharma lainnya yang melakukan kegiatan ritual pada pura tersebut. Dari kegiatan pengabdian yang dilakukan ini, diharapkan tercipta penataan mandala dan pelinggih berdasarkan pada rujukan dan kaidah yang tepat. Pura ini persembahyangan dilaksanakan setiap hari, pada hari-hari tertentu seperti keliwon, purnama, tilem, hari perayaan seperti saraswati, galungan, kuningan, siwalatri, nyepi serta hari piodalan.

Bertolak dari kondisi tersebut, pengemong mengajukan inisiatif untuk melakukan perbaikan/ pembangunan pada areal Pura Puja Dewata, yang mana dalam pelaksanaannya memerlukan bantuan teknis pembangunan berupa bimbingan dan pengawasan agar penataan dapat berjalan lancar dan sesuai dengan desain rencana yang telah dibuat. Kegiatan layanan bantuan teknis bimbingan dan pengawasan pembangunan dirangkaikan juga dengan kegiatan bakti social untuk mensinergikan antara kegiatan layanan bantuan teknis dan aktivitas social masyarakat setempat melalui Pengabdian Institusi Universitas Udayana periode 2017. Inisiatif ini mendapat dukungan penuh dari Universitas Udayana khususnya Jurusan Arsitektur Fakultas Teknik yang selama ini memang secara kontinyu memberikan dukungan teknis bagi penataan bangunan pura yang berada di wilayah sekitar Banyuwangi. sebagai salah satu perwujudan Tri Dharma Perguruan Tinggi.

\section{METODE PEMECAHAN MASALAH}

Kegiatan penataan yang diperlukan meliputi penataaan letak bangunan palinggih Gedong Dalem, palinggih pelengkap (Hyang Gagak dan Capah) dan bangunan pelengkap (Pyasan, Bale GongPesandekan dan penyengker) yang sesuai dengan hirarki hulu-teben. Memindahkan posisi pemedal 
utama yang berfungsi sacral berupa candi bentar ke arah barat, agar sesuai dengan arah bangunan palinggih Gedong Dalem yang merupakan bangunan utama dari pura dalem. Ke arah utara pada posisi pemedal semula akan menjadi paletasan untuk fungsi profan berupa candi bentar. Secara keseluruhan, teknis pelaksanaan tahapan dari kegiatan pengabdian ini meliputi :Studi Literatur, Focus Group Discussion /Diskusi, Observasi Lapangan, Analisis dan sintesis.

\section{HASIL DAN PEMBAHASAN}

Terdapat beberapa prinsip dalam tahapan pelaksanaan penataaan ini dituangkan dalam gambar rencana antara lain:

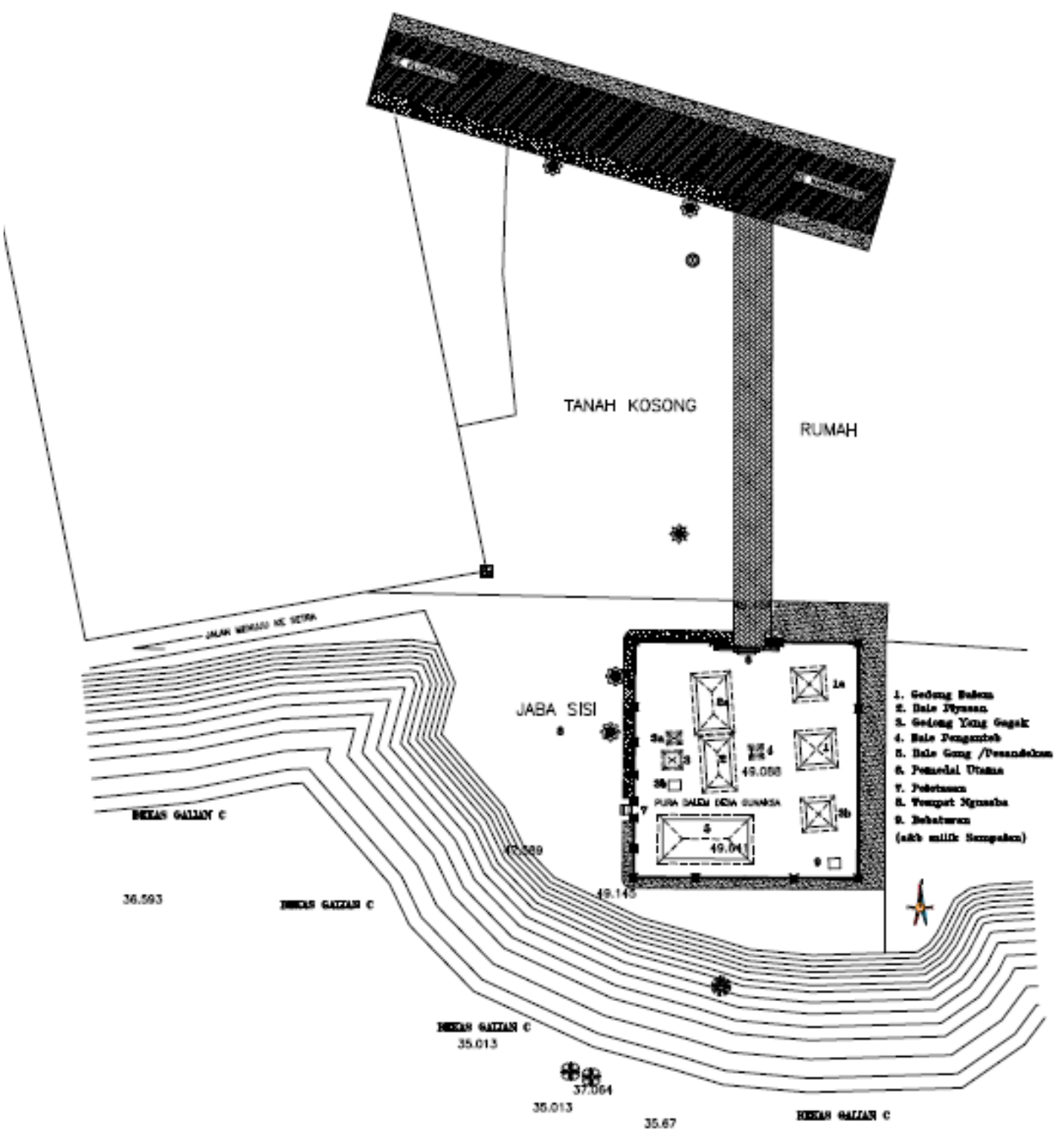

Gambar 3.1. Lay Out Lingkungan

Pura Dalem Desa Gunaksa 


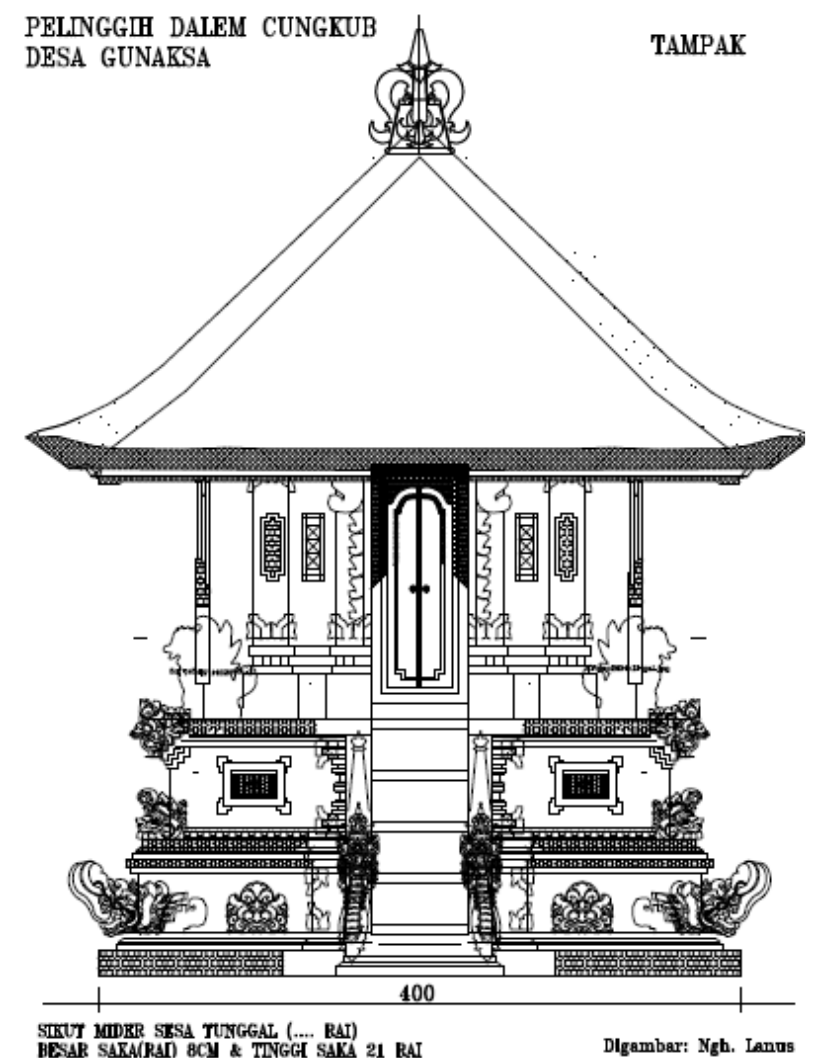

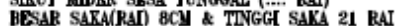

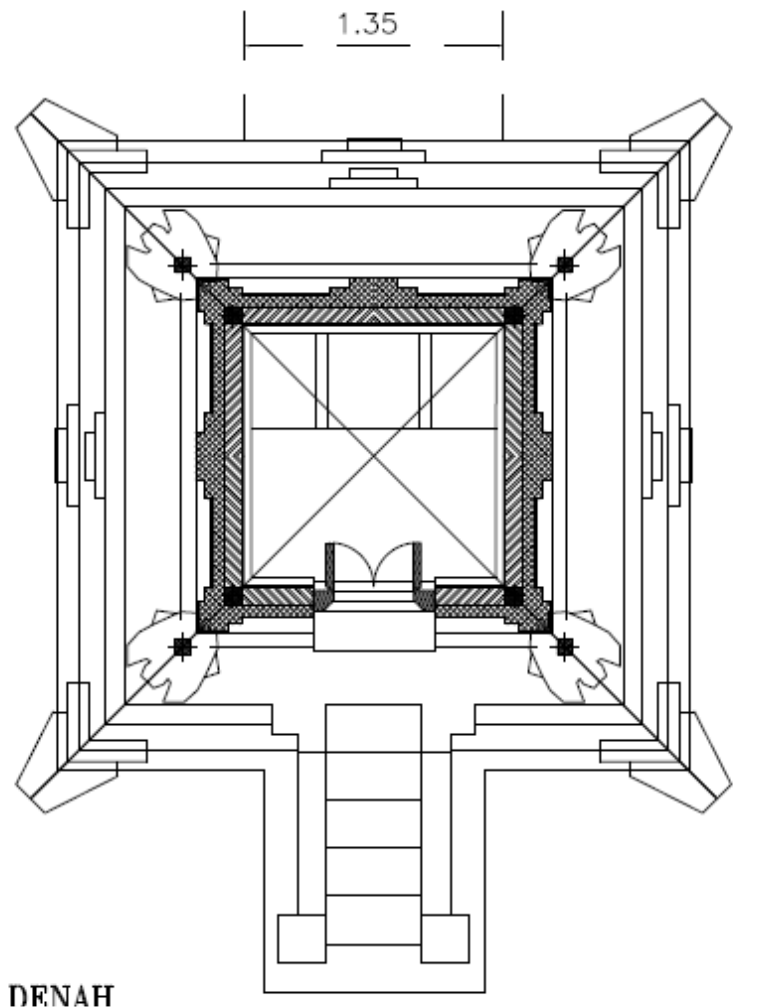

Gambar 3.2. Denah dan Tampak Palinggih Gedong Pura Dalem Desa Gunaksa 

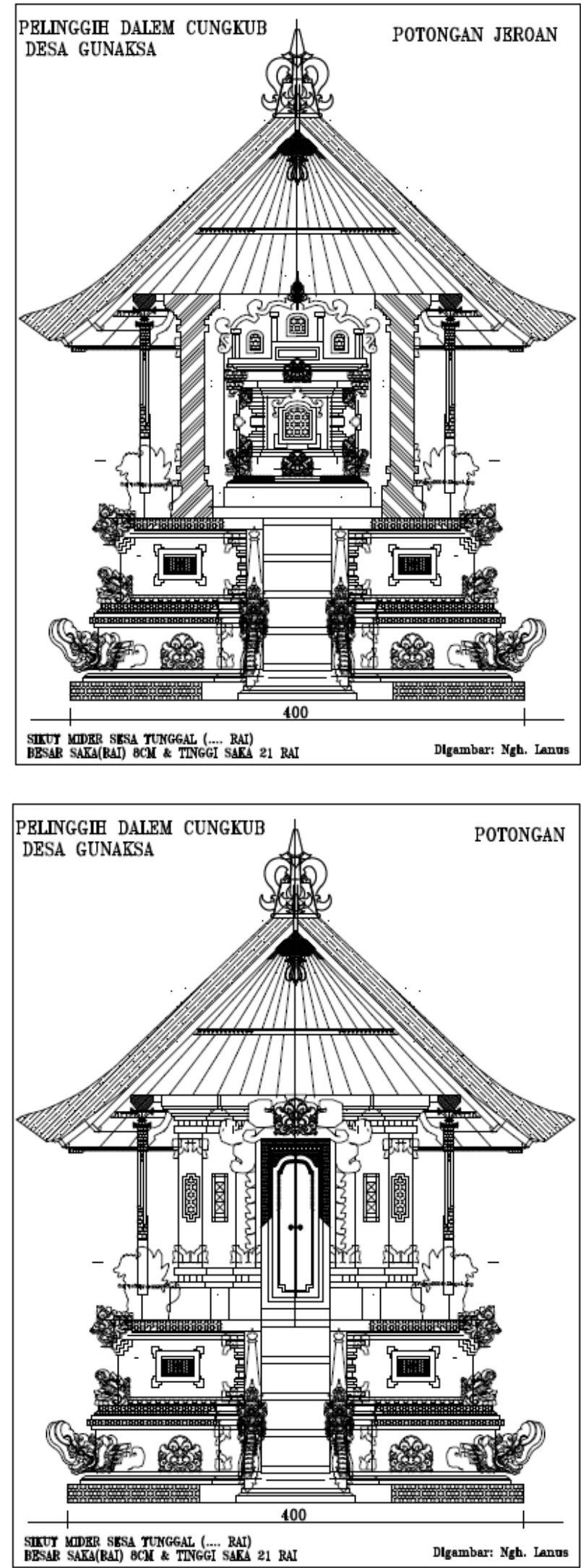

Gambar 3.3.Potongan Palinggih Gedong Pura Dalem Desa Gunaksa 


\section{KESIMPULAN DAN SARAN}

Kesimpulan yang dapat diambil melalui kegiatan pengabdian 'Penataan Pura Dalem Desa Gunaksa, Kecamatan Dawan, Kabupatan Klungkung, adalah bahwa pola pendekatan partisipatif pada suatu kegiatan, tidak hanya akan dapat memberikan hasil yang lebih maksimal serta sesuai dengan aspirasi masyarakat, namun dapat memberikan jaminan keberlanjutan kegiatan/program bahkan pengembangannya pada waktu-waktu yang akan datang.

\section{UCAPAN TERIMAKASIH}

Penghargaan yang setinggi-tngginya kepada masyarakat pengempon pura dan seluruh masyarakat Di Desa Gunaksa, Kecamatan Dawan, Kabupatan Klungkung. yang telah memeberikan kesempatan untuk berpartisipasi. Kepada Rektor Universitas Udayana dengan seluruh jajarannya yang telah memberikan dukungan dan bantuan dana untuk melaksanakan Pengabdian Institusi ini. Serta rekan-rekan tim pengabdi yang telah bekerja keras untuk menyelesaikan tugas dengan baik.

\section{DAFTAR PUSTAKA}

Gelebet, I Nyoman, dkk, 1985, Arsitektur Tradisional Bali- Proyek Inventarisasi dan Dokumentasi Kebudayaan Daerah, Departemen Pendidikan dan Kebudayaan, Ditektorat Jenderal Kebudayaan Direktorat Sejarah dan Nilai Tradisional, Denpasar

Patra, Made Susila, 1992, Hubungan Seni Bangunan dengan Hiasan dalam Rumah Tinggal Adati Bali, Penerbit Balai Pustaka, Jakarta

Pulasari, Jro Mangku, 2007, Cakepan Asta Kosala-Kosali, Penerbit dan Percetakan Paramita, Surabaya

Pulasari, Jro Mangku, 2008, Cakepan Asta Kosala-Kosali lanAsta Bumi, Penerbit dan Percetakan Paramita, Surabaya

Tonjaya, Bandesa K., 1982, Asta Kosali, Penerbit dan Toko Buku Ria, Denpasar

Widana, Ida Bagus Gede, 2011, Dharmaning Hasta Kosali - Arsitektur Tradisional Bali, Penerbit Dharma Pura, Denpasar. 